\title{
CRIATIVIDADE CIENTÍFICA: ASPECTOS EPISTEMOLÓGICOS
}

\section{ROBERTO GONÇALVES BARBOSA}

\author{
Universidade Federal do Paraná \\ E-mail: robertobarbosa@ufpr.br
}

\section{RESUMO:}

O objetivo deste trabalho foi o de promover pensamentos sobre práticas e conteúdos da Física ensinados nas escolas brasileiras, a partir de estudos que tratam da criatividade aplicada na Ciência, normalmente considerado um tema controverso, sobretudo, no processo de ensinar e de aprender Física. Trata-se da noção de criatividade que se tem hoje relacionada à produção de algo novo, ideia ou invenção original, bem como, ao aperfeiçoamento de ideias já existentes a partir da ação de um sujeito, ou de um grupo de pessoas. Diferentemente de estudos a respeito desse tema, geralmente realizados no campo da psicologia, recorremos aos próprios cientistas que tratam do assunto de forma direta ou indireta, fontes primárias, para compreender os aspectos criativos inerentes ao fazer Ciência. Como resultado, observa-se que a criatividade científica envolve aspectos pessoais como curiosidade, intuição, percepção, estética e imaginação, os quais podem ser tomados como objetivos educacionais em contraposição aos objetivos tradicionalmente estabelecidos por políticas educacionais.

\section{PALAVRAS-CHAVE:}

criatividade científica. ensino de física. epistemologia da ciência.

\section{SCIENTIFIC CREATIVITY: EPISTEMOLOGICAL ASPECTS}

\section{ABSTRACT:}

The objective of this work was to promote thoughts about practices and contents of Physics taught in Brazilian schools, based on studies that deal with creativity applied in Science, usually considered a controversial subject, especially in the process of teaching and learning Physics. It is the notion of creativity that is related today to the production of something new, idea or original invention, as well as to the improvement of existing ideas from the action of a subject or a group of people. Unlike studies of this subject, usually conducted in the field of psychology, we turn to the scientists themselves who deal with the subject directly or indirectly, primary sources, to understand the creative aspects inherent in doing Science. As result, it is observed that scientific creativity involves personal aspects such as curiosity, intuition, perception, aesthetics and imagination, which can be taken as educational objectives in opposition to the objectives traditionally established by educational policies.

\section{KEYWORDS:}

scientific creativity. physics teaching. epistemology of science. 


\section{INTRODUÇÃO}

Muitos são os desafios do ensino de Física no Brasil, destaca-se inicialmente a incapacidade política das entidades científicas brasileiras para a divulgação e implementação maciça dos resultados das pesquisas nacionais nas escolas brasileiras de modo mais amplo. Outro desafio é ultrapassar o caráter conteudista da Física, que se insere num modelo de ensino que se resume a levar o aluno a aprender fórmulas para aplicação em exercícios com pouca significação e, ainda, por ser este um ensino insuficiente para a promoção educacional-social dos sujeitos nele inseridos.

Neste panorama é preciso repensar os objetivos educacionais bem como a forma de organizar o ensino da Física, que de modo geral desconsidera a origem sociocultural dos estudantes bem como a base epistemológica sobre quais estão assentados os conceitos físicos. Ora, a escolha dos conteúdos e dos objetivos de ensino devem se pautar tanto nas necessidades intelectuais e carências sociais de nossos alunos, quanto nas habilidades e capacidades humanas desenvolvidas historicamente na edificação da Ciência, tais como a curiosidade, a imaginação, a criatividade, o trabalho coletivo e colaborativo, a habilidade de manipulação de objetos reais e imaginários, a criação e o manuseio de símbolos linguísticos e matemáticos.

Trata-se de características imprescindíveis para a criação e o estabelecimento da Ciência como herança cultural e campo de saber instituído, mas que não são exploradas nas aulas de Física.

Para realizar essa pesquisa fizeram-se duas questões: O que caracteriza a criatividade científica? Quais as suas possíveis contribuições para o ensino de Física? 


\section{METODOLOGIA}

Para este trabalho é elaborado um metatexto a respeito da criatividade científica a partir de reflexões de físicos, químicos, matemáticos e filósofos que tratam do assunto de forma direta ou indireta, para compreender os aspectos criativos inerentes ao fazer Ciência bem como para buscar/construir respostas ao problema proposto. Para discussão dos dados faz-se uma análise textual em que se destacam as unidades significativas e os termos significativos para responder as questões do problema de pesquisa.

\section{CRIATIVIDADE E CRIATIVIDADE CIENTÍFICA}

A noção de criatividade que se tem hoje se refere a elaboração de algo novo, ideia ou invenção original bem como do aperfeiçoamento de produtos ou ideias já existentes, a partir da ação de um sujeito ou de um grupo de pessoas (ALENCAR, 2003). Essa noção pode ser tomada, segundo Kneller (1979), a partir de quatro perspectivas: da pessoa que cria (personalidade, valores, hábitos); dos processos mentais (cognitivo, pensamento e comunicação); das influências ambientais e culturais, bem como em função dos seus produtos como teorias, invenções, esculturas e poemas. Na Ciência de modo particular, podemos destacar pessoas ${ }^{1}$ criativas (Newton, Einstein, Darwin) e também produtos criativos (teorias, leis, hipóteses), a maior dificuldade, porém reside no reconhecimento dos processos mentais, emocionais e físicos do sujeito criativo envolvidos no momento da criação. E com o objetivo de melhorar a compreensão a respeito desses processos na prática científica, debruça-se sobre os trabalhos dos próprios cientistas, com objetivo de obter um olhar mais preciso da ideia de criatividade científica, sua natureza.

\footnotetext{
${ }^{1}$ Com rara menção a mulheres ou a pessoas de outras nacionalidades exceto europeia, como árabes, chineses ou africanos.
} 


\subsection{Criatividade Cientifica: Percepção E Totalidade}

Para o patologista animal o australiano Willian I. Beveridge (1981) a criatividade científica consiste na percepção de novos padrões significativos de partes do conhecimento - dados e teorias - já disponíveis, exatamente como um compositor cria uma nova melodia imaginando um novo arranjo de notas musicais ao combinar, relacionar e integrar peças de informação até então separadas, um novo modelo de pensamento, isto é, a ideia é criada. Para o físico David Bohm (2011), a descoberta de algo novo e realmente criativo existe a partir da "percepção de uma nova ordem básica potencialmente significativa em uma área mais ampla e rica. Essa nova ordem leva no final a criação de novas estruturas que tenham as características de harmonia e totalidade e, portanto a sensação de beleza" (BOHM, p.7, 2011). Nesta perspectiva, a ordem é entendida como uma forma de organização de coisas que nem sempre são possíveis de descrever, pois não temos a percepção completa de uma determinada situação ou fenômeno. Para Bohm (2011), por exemplo, o movimento caótico de partículas não é uma desordem total, mas uma ordem passível de infinitas regularidades difíceis de serem percebidas. O outro termo, a estrutura se refere à ordenação de elementos que constituem certa ordem, por exemplo, elétrons e partículas nucleares ordenadas de certa forma constituem os átomos, esses últimos ordenados, constituem a matéria sólida, líquida e gasosa e assim sucessivamente. E nessa ordem hierárquica, aparece ou se percebe uma totalidade harmoniosa, as simetrias, as regularidades que possibilitam novos arranjos o que ele considera ser uma estruturação criativa da própria natureza. Em resumo,

Em um ato de percepção criativa, o indivíduo torna-se, primeiro, consciente (normalmente de forma não verbal) de uma nova série de diferenças relevantes e começa a examinar ou observar uma série de semelhanças, as quais não vêm simplesmente de conhecimento prévio, tanto do mesmo campo como de um novo. Isso leva a uma nova ordem que favorece o 
surgimento de uma nova hierarquia de ordens que constituem uma série de novos tipos de estrutura. O processo tende a formar totalidades harmoniosas e unificadas, com a sensação de beleza, e é capaz de mover aqueles que a entendem de uma forma profundamente inspiradora (BOHM, 2011, p.19).

Tal situação não ocorre frequentemente, pois é preciso um estado de espírito criativo livre de preconceitos, contrário ao que a escola, a família e a sociedade cultivam: um espírito conformista, imitador, mecânico e não perturbador. Bohm (2011), nesse sentido, salienta que o espírito criativo é sincero como de uma criança que está aberta a aprender o novo. O filósofo Francês Abraham Moles (1971) afirma também que a capacidade de espanto é uma característica fundamental do cientista, isto é, "essa capacidade de espanto renovada, este frescor de espírito é uma virtude infantil; o homem mais idoso, normal, quase não a possui. Ele substitui as suas experiências por lembranças e sua imaginação por hábitos" (MOLES, 1971, p.94), do mesmo modo Beveridge (1981) lembra que "as ideias originais surgem facilmente antes da plena maturidade, antes que os hábitos de pensar se tornem enraizados" (BEVERIDGE, 1981, p.103) o que permite reconhecer que o cientista, independentemente de sua idade, carrega consigo essa característica infantil que mistura espanto, ingenuidade e curiosidade.

\subsection{A Criatividade NA TeORIZAÇÃo CientífICA}

As teorias científicas são possivelmente as maiores criações da Ciência, é possível afirmar portanto que elas são "tentativas permanentes de síntese total, que fornecem o quadro doutrinário do campo de visão: elas são grandes linhas do edifício científico [...] e conservam sempre um aspecto fortemente dogmático mesmo sabendo que são essencialmente provisórias" (MOLES, 1971, p.151) e, de certo modo

são normativas que pretendem reger o domínio do qual se ocupa em nome da inteligibilidade do universo, da racionalidade do real. Ela é 
fundamentalmente idealista, porquanto se impõe a priori, não apenas aos fatos conhecidos, mas aos vindouros. Ao menos no quadro elementar, é uma grade cujas casas estão vagas e prontas para receber as doutrinas secundárias, suscetíveis de variações consideráveis de textura, pois este quadro da grande teoria é ao mesmo tempo sólido e deformável localmente, sem que a forma do seu conjunto seja substancialmente modificada, sendo procedimento idealizante precisamente o de fazer dobrar o perceptível ao inteligível e o inteligível ao geral, em sistema de mundo sem lacuna (MOLES, 1971, p.151)

Ademais, a abordagem paradigmática da Ciência dada por Kuhn vê as teorias como exemplos simplificados da natureza, que contribuem para revelar relacionamentos essenciais para a observação e a experiência.

Tais teorias são criações do cientista, interpretadas em parte com base em sua beleza - harmonia, ordem, elegância, totalidade unificada, e assim por diante - e em parte por sua habilidade de ajudar a entender diversos fatos científicos - isto é, integrá-los a uma estrutura ainda mais ampla e coerente. Tal entendimento inclui a habilidade de sugerir novas relações que valem uma investigação mais detalhada, tanto teórica como experimental. Assim, a teoria exerce um papel dinâmico e criativo, não restrito a um entendimento passivo do que já é conhecido, mas também prosseguindo para "manter-se a frente" do conhecimento, antecipando o que pode vir a acontecer mais tarde, bem como sugerindo novas "relações paradigmáticas" com a natureza, para serem determinadas por experiências e para servirem como base para criações de teorias em escalas ainda maiores (BOHM, 2011, p.40).

Como se percebe, as teorias científicas oferecem uma visão ideal e global do mundo, obrigando o real percebido a se integrar as suas estruturas, pelo menos é o que pretendia a ciência clássica. Com o advento da relatividade, da Física do não equilíbrio e da mecânica quântica, nas quais a certeza dá lugar à incerteza e o geral dá lugar ao particular, e as leis que descreviam cirurgicamente o comportamento de uma partícula individual se tornam obsoletas quando observadas de muito perto, pois, inúmeras flutuações interferem em sua trajetória; logo para atender essa nova realidade propôs-se formular novas teorias a partir de totalidades e situações 
estatísticas; "as leis assim concebidas não nos dizem o que vai acontecer, mas o que pode acontecer" (PRIGOGINE, 2009, p.97).

Em si mesmo, esse desenvolvimento constitui um exemplo de criatividade singular da Física, nascida do diálogo entre as exigências de experimentação e da inventividade da linguagem matemáticas. O grande edifício das leis clássicas e quânticas da física traduz essa mesma criatividade. Para modificá-lo, não era suficiente apelar à hipótese ad hoc ou a argumentos de bom senso. É somente porque novos instrumentos matemáticos, que não existiam na época de Boltzman e novos problemas físicos como aqueles que descrevem os sistemas dinâmicos instáveis ou caóticos nos permitem formular novas exigências e questões, que a resolução do paradoxo pode satisfazer que preside a história da Física, ou seja, pressupõe a construção de uma relação sempre mais forte entre pertinência experimental e invenção matemática (PRIGOGINE, 2009, p.60).

Nessa perspectiva, a probabilidade representa possibilidade e não verdade, o mundo físico se abre e o homem passa a fazer parte dele juntamente com as noções de acontecimento, novidade e criatividade. Assim, a visão reducionista de que a ciência é uma construção que se dá de forma lógica e racional dá lugar a um processo que envolve entre outras coisas, o gosto estético, a imaginação, a intuição e ao acaso.

\subsection{O ACASO}

O acaso talvez seja um dos aspectos mais citados quando se refere às descobertas científicas seja na escolha arbitrária de instrumentos e amostras seja pela deteç̧ão de um elemento incomum ou inesperado. Para Beveridge (1981), a maioria das descobertas que abrem novos campos é, por sua própria natureza, imprevisível e por isso o modo quase único de fazer descoberta é esbarrar por acaso em algum indício, ter a sorte de encontrar uma pista não imaginada. Em seu livro "A arte da investigação científica", o autor apresenta inúmeros exemplos de descobertas que se deram por casos fortuitos. Entre os quais se destacam a observação da contração muscular da perna de uma rã pela eletricidade pelo 
fisiologista italiano Luigi Galvani, da observação da deflexão de uma agulha magnetizada próxima a um fio eletrificado, pelo físico holandês Oersted em 1822. 0 acaso, também, muitas vezes, pode vir seguido de outro elemento, a intuição, termo encontrado em obras de Einstein, Poincaré e Enrico Fermi, da obra deste ultimo, o físico Gerald Holton (1979) cita uma conversa que o mesmo teve com o astrofísico S. C. Chandrasekhar, em que relata sua experiência intuitiva,

Vou lhe dizer como fiz a descoberta que considero a mais importante das que fiz. Estávamos trabalhando duramente na radioatividade induzida por nêutrons, e os resultados que obtínhamos não faziam sentido. Certo dia, ao chegar ao laboratório, ocorreu-me que deveria examinar o efeito de colocar um pedaço de chumbo ante os nêutrons incidentes. Em lugar do processo habitual, empenhei-me em conseguir um pedaço de chumbo nas medidas e especificações precisas. Evidentemente, alguma coisa me descontentava: usei todas as "desculpas" para adiar a colocação do chumbo no seu lugar. Quando finalmente com alguma relutância, eu ia colocá-lo, disse a mim mesmo: Não, não quero este pedaço de chumbo aqui; o que eu quero é um pedaço de parafina... e o coloquei onde deveria ter sido posto o chumbo (HOLTON, 1979, p.141).

Como se nota, não se sabe o que o fez substituir o chumbo pela parafina, quando isso acontece diz-se que o que moveu foi sua intuição, um sentimento de certeza cuja a razão era desconhecida. Para Beveridge (1981) o mais extraordinário sobre a "intuição é que não chegamos a ela através de uma sequência consciente de pensamentos, ela aparece espontaneamente. Sem dúvida ela se desenvolve no subconsciente; proporciona excitação e prazer" (BEVERIDGE, 1981, p.9). Todavia muitas vezes a intuição é confundida com a ideia de iluminação, um dos estágios do processo de descoberta elencados por Graham Wallas (1924). Neste caso, quando a resposta a um problema surge inesperadamente ou de repente, após ter sido pensada por algum tempo, diz-se que o mesmo teve um insight ou iluminação, segundo Moles (1971), a iluminação é um momento frequentemente muito breve, é um clarão no pensamento: subitamente a forma encontra seu fecho, sua realização, 
a tensão se relaxa em um esquema original, é a solução, que é ao mesmo tempo uma dissolução do problema colocado. Um exemplo desse momento é dado pelo matemático Henry Poincaré;

Foi no instante em que pus o pé no estribo do ônibus de Coutances que me veio a ideia de que as transformações que eu havia utilizado para definir as funções fuchsianas eram idênticas às da geometria não euclidiana e eu o senti com uma certeza perfeita (MOLES, 1971, p.164).

Para Bohm (1967), o acaso é um fenômeno contingente, isto é, "representa essencialmente fatores independentes que existem fora do escopo das leis consideradas, e que não seguem necessariamente qualquer padrão que esteja no contexto dessas leis" (BOHM, 1967, p.2). E como esses efeitos não podem ser negligenciados, no estudo da física quântica, por exemplo, faz-se necessário considerar a interpretação probabilística que poderá ser usada para fazer predições aproximadas a partir da observação de regularidades relativas.

A física clássica [...] na medida em que ela associa a apresentação de processos objetivos no espaço e no tempo desde o inicio com pressuposição da completa determinação desses processos. Ela projeta a imagem de sistemas espaciais, de sistemas materiais encerrados pelo mundo exterior, cujo transcurso temporal é determinado a partir de seu estado presente para todo o futuro. Em contraposição a essa idealização, o conceito de estado da teoria quântica traz consigo uma situação completamente nova para a questão da determinação dos processos naturais. [...] Na região da realidade, cujas conexões são formuladas pela física quântica, portanto, as leis naturais não conduzem a uma fixação completa daquilo que acontece no espaço e no tempo; o acontecimento é muito mais entregue ao jogo do acaso (HEISENBERG, 2009, p.70).

Assim, o mundo estável e de trajetórias determinadas matematicamente é substituído pela instabilidade e pelo acaso, o que permite uma diversidade de comportamentos imprevisíveis que segundo Prigogine (2009):

[...] até "Einstein teve de admitir que a descrição à respeito do átomo quântico devia integrar também a lei e o acontecimento. A propósito da emissão espontânea de luz pelo átomo excitado, ele escreveu: o momento 
e a direção dos processos elementares são determinados pelo acaso" (PRIGOGINE, 2009, p,53).

É este o pensamento revolucionário da ciência moderna.

Não usa outro princípio que não seja o da previsão com a máxima segurança possível, mas não mais do que a possível. Isto é, idealiza o futuro [...]" não como completamente determinado, mas como determinado dentro de uma área definida de incerteza. (BRONOWSKI, 1983, p.100).

\subsection{A IMAGINAÇÃO}

A imaginação na Ciência geralmente está relacionada à visualização de imagens, à experimentação mental, à busca imagética de novas relações e modelos, simulações e até fantasias, conquanto que sejam submetidas ao crivo da razão. Segundo Beveridge (1957):

[...] a imaginação é de grande importância não apenas para nos levar a novos fatos, mas também a nos estimular a novos esforços, por isso nos capacita imaginar possíveis consequências. Os fatos e as ideias em si são mortos e é a imaginação que lhes dá vida. Mas sonhos e especulações são fantasias inúteis a menos que a razão use-as para um propósito útil, por isso ideias vagas e fantásticas devem ser reduzidas a hipóteses e proposições específicas (BEVERIDGE, 1957, p.78).

Para o matemático Jacob Bronowski (1997), a imaginação é uma palavra que deriva da criação de imagens na mente, a partir do que Wordsworth (1997 p. 11) chamou de olho interior fato que permite pensar que nossas capacidades mentais de memória e imaginação, simbolismos e de símbolos, estão condicionadas ao sentido da visão quer dizer, as imagens mentais resultam de nossa experiência sensorial anterior. Mas isso não significa que as imagens mentais não possam ter padrões novos e originais. Um exemplo deste aspecto é o estabelecimento da queda da Lua por Isaac Newton, um exemplo de "percepção imaginativa" Bohm (2011). Para Beveridge (1957), esse processo ocorre repentinamente quando a pessoa percebe pela primeira vez uma conexão entre diversos objetos ou ideias, ou quando dá um 
grande salto para frente ao invés dos habituais "passos curtos" na região onde as conexões das ideias estão bem estabelecidas e óbvias. Um outro aspecto também apontado por Bronowski (1997) é que a imaginação ajuda tanto na delimitação de um sistema, por meio de um simbolismo, quanto na abertura deste para novas conexões. Ademais o ato de imaginação consiste na descoberta de semelhanças entre duas coisas distintas tais como Lua e maçã. Uma semelhança improvável mas que, no entanto, se mostrou enormemente produtiva.

Todos os atos de imaginação são desta natureza. Eles abordam o sistema fechado, inspecionam-no, manipulam-no e, depois, descobrem algo que até então não havia sido colocado no sistema. Então abrem o sistema, introduzem novas semelhanças, seja como Shakespeare dizendo: "My mistress' eyes are nothing like the Sun" ", ou Newton afirmando que a Lua, na sua essência, é exatamente igual a uma maçã caindo. Todos os que usam a imaginação tomam partes do universo que ainda não haviam sido previamente relacionadas, ampliam a conectividade total do universo, mostrando que estão interligadas (BRONOWSKI, 1997, p.65).

Em resumo, a criatividade e a imaginação na Ciência parecem resultar da nossa limitação, o que felizmente torna impossível abarcar o universo por completo e dessa premissa entende-se a construção da Ciência como um processo que passa primeiramente pela delimitação ou recorte de um objeto ou sistema para estudo que leva a uma explicação muito superficial do real, depois de considerar o que é relevante para o experimento é então que passamos a decodificá-lo, interpretá-lo, em cujo processo utilizamos a imaginação, inventamos entidades, conceitos mesmo sem possuirmos evidência direta de sua existência: gravidade, massa, elétron. Como exemplo, o autor recorre a Isaac Newton com relação ao dia em que ele concebeu a fórmula da gravitação universal. Segundo Bronowski (1997), Newton disse a si mesmo:

\footnotetext{
${ }^{2}$ Os olhos de minha amante, não são nada como o Sol.
} 
Se eu jogar uma bola ela cairá no solo. Se a jogar com mais força, cairá um pouco mais longe. Tenho de conseguir atirá-la com a força exata para que caia exatamente na linha do horizonte e então, ela dará a volta ao mundo". Lindo, em 1666 não se podia comprovar tal hipótese, é claro, mas eu não posso jogar uma bola em volta do mundo, mas posso imaginar a Lua como se fosse uma bola que tem estado a rolar em torno do mundo (BRONOWSKI, 1997, p.39).

\section{SÍNTESE E ANÁLISE}

\subsection{CRIATIVIDADE CIENTífICA}

Quadro 1 - Unidades significativas e termos significativos. Fonte: 0 autor.

\begin{tabular}{|c|c|c|}
\hline X & Unidade significativa & Termos significativos \\
\hline Beveridge & $\begin{array}{l}\text { [...] percepção de novos padrões significativos de } \\
\text { partes do conhecimento - dados e teorias - já } \\
\text { disponíveis, exatamente como um compositor cria } \\
\text { uma nova melodia imaginando um novo arranjo de } \\
\text { notas musicais ao combinar, relacionar e integrar } \\
\text { peças de informação até então separadas, um novo } \\
\text { modelo de pensamento, isto é, a ideia é criada. }\end{array}$ & $\begin{array}{l}\text { a) Percepção de novos } \\
\text { padrões. } \\
\text { b) Combinação ou } \\
\text { integração de partes da } \\
\text { realidade. } \\
\text { c) imaginação, percepção } \\
\text { imaginativa. } \\
\text { d) Acaso. }\end{array}$ \\
\hline Bohm & $\begin{array}{l}\text { Percepção de uma nova ordem básica potencialmente } \\
\text { significativa em uma área mais ampla e rica. Essa nova } \\
\text { ordem leva no final a criação de novas estruturas que } \\
\text { tenham as características de harmonia e totalidade e, } \\
\text { portanto a sensação de beleza. }\end{array}$ & $\begin{array}{c}\text { a) percepção de uma nova } \\
\text { ordem. } \\
\text { b) Harmonia, totalidade e } \\
\text { beleza. } \\
\text { c) Espírito criativo, } \\
\text { abertura. }\end{array}$ \\
\hline Moles & Resulta de novas relações. & $\begin{array}{c}\text { a) Espírito criativo } \\
\text { (espanto infantil), intuição. }\end{array}$ \\
\hline Prigogine & $\begin{array}{l}\text { (mecânica quântica) nascida do diálogo entre as } \\
\text { exigências de experimentação e da inventividade da } \\
\text { linguagem matemáticas. }\end{array}$ & \\
\hline Bronowski & $\begin{array}{c}\text { Imaginação - imagens mentais que resultam de nossa } \\
\text { experiência sensorial. }\end{array}$ & a) Imaginação. \\
\hline
\end{tabular}

Por meio dos termos significativos e das unidades significativas assim classificadas é possível inferir que os cientistas referenciados definem a criatividade científica como uma capacidade que os cientistas têm em perceber novas relações entre conceitos ou entre entes físicos, bem como combinar diferentes elementos da experiência, quer dizer, elementos resultantes do contato com as teorias científicas 
ou com o próprio objeto de investigação. Esta capacidade parece estar vinculada a uma liberdade ou autonomia de pensamento e ação que faz com que o/a cientista crie, combine e imagine outras possiblidades interpretativas para o mundo natural, sua organização.

\subsection{POSSÍVEIS CONTRIBUIÇÕES PARA O ENSINO DA FÍSICA - UMA REFLEXÃO}

Pela análise anterior é possível notar que os cientistas citados quando remetem a criatividade científica referem-se ao sujeito criador, suas características pessoais como curiosidade, imaginação, gosto estético e abertura. Características que nos levam a indagar se nas aulas tradicionais de Física há momentos em que os estudantes são solicitados a darem outras explicações para os fenômenos já conhecidos ou para outros desconhecidos, momentos em que eles usem sua própria linguagem e imaginação para criação de novas, entidades, hipóteses ou teorizações.

Tais questionamentos associados às práticas tradicionais de reprodução e acumulação de conceitos e terminologias da Física que ocorrem na grande maioria das escolas e universidades brasileiras, nos permite afirmar que este modelo de ensino tem um grande poder inibidor da expressão e do espírito criativo dos estudantes brasileiros, uma afirmação que vai ao encontro das palavras da pesquisadora brasileira em criatividade, Eunice Soriano de Alencar (2004) que afirmou que no Brasil o potencial humano tem sido subutilizado, permanecendo muitas capacidades inibidas e bloqueadas por falta de estímulo, encorajamento e de um ambiente favorável a seu desenvolvimento. Segundo ela, isto ocorre de maneira mais significativa entre sujeitos do sexo feminino e das camadas de baixa renda (ALENCAR, 2004). 


\section{CONSIDERAÇÕES FINAIS}

No que tange aos aspectos epistemológicos discutidos, observa-se que a percepção, a curiosidade, a intuição e a imaginação se destacam como características pessoais, assim como a lógica e a razão presentes no processo de elaboração da Ciência. Tais aspectos nos permitem pensar novos objetivos educacionais para as aulas de Ciências, pois, de modo geral, os objetivos de ensino coincidem com os conhecimentos científicos - conceitos, leis, símbolos, unidades de medida, fórmulas - a serem aprendidos em contraposição ao desenvolvimento da criatividade e da imaginação, que podem ser tomadas como características pessoais a serem desenvolvidas nas aulas de Física/Ciências.

Nesta perspectiva, a seleção dos conteúdos e da metodologia estariam subordinadas à expressão criativa e ao uso da imaginação, o que ocorre, por exemplo, quando um professor solicita que os alunos elaborem analogias considerando as diferentes ligações químicas (MENDONÇA, JUSTI, OLIVEIRA, 2006) ou que descubram o formato geométrico oculto sob uma placa de madeira quando se lança bolinhas de gude, simulando o experimento do espalhamento atômico de Rutherford (GURGEL e PIETROCOLA, 2011).

São exemplos nos quais os professores desafiam os alunos a imaginar, a criar e também a aplicar os conhecimentos que aprenderam. Atividades que transcendem a mera reprodução de conhecimentos em exercícios padronizados. Práticas que partem de estudos a respeito da natureza da Ciência as quais podem contribuir principalmente para a busca pela resposta da seguinte questão: O que se pode ensinar nas aulas de Física/Ciências que não seja propriamente os conteúdos conceituais presentes nos livros didáticos? 


\section{REFERÊNCIAS}

ALENCAR, Eunice. S. de. Como desenvolver o potencial criador: um guia para a liberação da criatividade em sala de aula. 10.ed. Petrópolis: Editora Vozes, 2004.

ALENCAR, Eunice. S. de. Criatividade: múltiplas perspectivas. 3.ed. Brasília: Editora Universidade de Brasília, 2003.

BEVERIDGE, W. I. B. Sementes da descoberta científica. Trad. S. R. Barreto. São Paulo: 2o ed. EDUSP, 1981.

BEVERIDGE, W. I. B. The Art of Scientific Investigation. New York: third edition vintage Books, 1957.

BRONOWSKI, Jacob. Introdução a Atitude Científica. Lisboa: 2o ed. Livros horizonte, 1983.

BRONOWSKI, Jacob. As origens do conhecimento e da Imaginação. Trad. Maria Julieta de Alcântara Carreira Penteado. Brasília: 2ee. Ed. UnB, 1997.

GURGEL, Ivan. E PIETROCOLA, Maurício. O papel da imaginação no pensamento científico: análise da criação científica de estudantes em uma atividade didática sobre o espalhamento de Rutherford. Caderno Brasileiro de Ensino de Física, v.28, n.1, 2011.

HOLTON, Gerald. A Imaginação científica. Trad. Waltensir Dutra. Rio de janeiro: Ed. Zahar, 1979.

KNELLER, George F. Arte e Ciência da Criatividade. Tradução de José Reis. São Paulo: 15a ed. IBRASA, 1979.

MENDONÇA, P. C. C.; JUSTI, R.; OLIVEIRA. M. M. Analogias sobre ligações químicas elaboradas por alunos do ensino médio. Revista Brasileira de Pesquisa em Educação em Ciências, v.6, n.1, 2006.

MOLES, Abraham. A Criação científica. Ed. Universidade de São Paulo. Trad. Gita K. Guinsburg. São Paulo: Ed. Perspectiva, 1971.

BOHM, David. Causality and Chance: in Modern Physics. London: 4o ed. Routledge \& Kegan Paul LTD, 1967.

BOHM, David. Sobre a criatividade. Trad. Rita de Cássia Gomes. São Paulo: ed. Unesp, 2011.

HEISENBERG, Werner. A ordenação da realidade. Trad. Marco Antônio Casanova. Rio de Janeiro:

Ed. Forense Universitária, 2009. 
PRIGOGINE, Ilya; STENGERS, Isabelle. A nova Aliança: metamorfose da ciência. Trad. Miguel Faria e Maria Joaquina Machado Trincheira. Brasília: Ed. Universidade de Brasília, 1991.

Recebido em: Junho de 2017. Publicado em: Abril de 2018. 